\title{
Characterization and Shelf Life of $\beta$-Carotene Loaded Solid Lipid Microparticles Produced With Stearic Acid and Sunflower Oil
}

\author{
Graziela Veiga de Lara Gomes ${ }^{1}$, Thais Ribeiro Borrin ${ }^{1}$, Lisandro Pavie Cardoso ${ }^{2}$, Eliana \\ Souto $^{3}$ and Samantha Cristina de Pinho ${ }^{1 *}$ \\ ${ }^{I}$ Departamento de Engenharia de Alimentos; Universidade de São Paulo; Pirassununga - SP - Brasil. \\ ${ }^{2}$ Departamento de Física Aplicada; Universidade Estadual de Campinas; Campinas - SP - Brasil. ${ }^{3}$ Universidade \\ Fernando Pessoa; Porto - Portugal
}

\begin{abstract}
Solid lipid microparticles were tested as microencapsulation systems for protecting $\beta$-carotene from degradation. Blends of long-chain (C18) solid lipids (70\% stearic acid) and sunflower oil (30\%) were used to produce lipid microparticles encapsulating the carotenoid. Polysorbate 80 (4\%) was employed to stabilize the stearic acid microparticles. The concentration of $\beta$-carotene was monitored using spectrophotometry, the particle size distribution was measured by laser diffraction, the crystal structure was determined by wide angle X-ray diffraction (WAXD), and the thermal behaviour was characterized by differential scanning calorimetry (DSC) over a period of seven months. All of the systems had an average particle size smaller than $5 \mu \mathrm{m}$. To avoid $\beta$-carotene oxidation, $\alpha$ tocopherol was added to the formulations and its action as an oxygen trap was crucial for the antioxidant effect. For stearic-acid microparticles with $\alpha$-tocopherol, more than $90 \%$ of the initial amount of $\beta$-carotene was preserved after seven months under refrigerated storage $\left(7-10^{\circ} \mathrm{C}\right)$ in the dark. Significant microstructural alterations were detected using WAXD and DSC only in the stearic acid microparticles without alpha-tocopherol. These results seemed promising and suggested that the blends of long-chain solid lipids and liquid lipids were suitable for the production of stable solid lipid microparticles.
\end{abstract}

Key words: solid lipid microparticles, $\beta$-carotene, microencapsulation

\section{INTRODUCTION}

Some vitamins (A, D, E) and carotenoids are liposoluble compounds that are naturally present in the food, or are used as excipients in different industrial products, such as pharmaceuticals, cosmetics, or foods (Gonnet et al. 2010). Carotenoids are among the most investigated lipophilic bioactive compounds due to their numerous beneficial roles in human health because of their potential as prophylatic and therapeutic agents for the diseases such as hypertension, diabetes, cardiovascular diseases and some types of cancer (Fraser and Bramley 2004; Ratnam et al. 2006). Carotenoids are also one of the most important groups of natural pigments because they are widely distributed in the plants (Yuan et al. 2008; Papaioannou and Liakopoulou-Kyriakides 2010). There are several types of carotenes, but one of the most important is $\beta$-carotene due to its

*Author for correspondence: samantha@usp.br 
high provitamin A activity and antioxidant capacity (Hentschel et al. 2008; Cao-Hoang et al. 2010). However, it is highly hydrophobic and, thus, only marginally soluble in aqueous media. Even in relatively lipophilic environments, only a small proportion of the molecules are found in the monomolecular form. Additionally, due to its high degree of instauration, it is very sensitive to oxidation upon exposure to oxygen, heat or light (Damodaran et al. 2010; Boon et al. 2010).

Lipid-based matrices are known to improve the bioavailability of hydrophobic bioactives, which make these matrices especially interesting as encapsulation systems. Recent advances have shown that one of the approaches to improve the solubility and bioavailability of poorly soluble substances, such as carotenes and tocopherols, is to incorporate these compounds in lipid-based encapsulation systems (Helgason et al. 2008, Helgason et al. 2009; Nik et al. 2011; Shukat and Relkin 2011; Wang et al. 2012). Several structured lipid-based delivery systems are available to encapsulate, protect and deliver the hydrophobic bioactive compounds in the form of lipid droplets (emulsions, microemulsions, nanoemulsions, multiple emulsions), liposomes, coated particles (multilayer emulsions, colloidosomes) and solid lipid particles (McClements 2010; McClements and Li 2010). Solid lipid particles, which can be produced at either the micro-, or nanoscale, are generated by exchanging the liquid core (oil), composed of a conventional oil-in-water $(\mathrm{o} / \mathrm{w})$ emulsion, for a solid lipid (lipids that are solid at room temperature) (Müller et al. 2002). The advantages of using these particles to load the active ingredients, such as $\beta$-carotene, are good biocompatibility, biodegradability and high capacity for incorporating hydrophobic compounds.

The aim of this study was to characterize and evaluate the shelf life of $\beta$-carotene-loaded solid lipid microparticles produced with a mixture of a long-chain fatty acid (stearic acid) and sunflower oil. Before producing the solid particles, characterization of the bulk lipid mixtures was carried out to rationalize the choice of a suitable lipid blend. Using the chosen blend, the solid lipid particles encapsulating $\beta$-carotene were produced and their capacity for preserving the carotenoid over the storage period was monitored. The need for an antioxidant ( $\alpha$-tocopherol) to help the preservation of $\beta$-carotene was also evaluated. The solid lipid particles were analyzed in terms of crystallinity (by wide-angle X-ray diffractometry), thermal behaviour (by differential scanning calorimetry) and particle size distribution (by laser diffraction) over the storage time.

\section{MATERIALS AND METHODS}

\section{Material}

$\beta$-Carotene, stearic acid (SA) and $\alpha$-tocopherol were obtained from Sigma (St. Louis, USA). Sunflower oil (SO) was obtained from Cargill (Mairinque, Brazil), while the polysorbate 80 (Tween 80®) was obtained from Synth (Diadema, Brazil). All of the reagents used in this study were reagent grade. Ultra-pure water (from a Millipore system) was used throughout the experiments.

\section{Production of bulk lipid matrices}

The bulk, solid lipid (stearic acid) and binary mixtures (stearic acid + sunflower oil) were analyzed separately. The lipid mixtures contained 10 and $30 \%$ sunflower oil (by mass) with the remaining mass attributed to stearic acid. Fusion consisted of melting in a thermostatic water bath at $80^{\circ} \mathrm{C}$. After fusion, the samples were kept at room temperature until they were completely cooled and solidified.

\section{Production of $\beta$-carotene-loaded solid lipid microparticles}

Solid lipid microparticles were produced by melting the lipid phase (30\% sunflower oil $+70 \%$ stearic acid) at $80^{\circ} \mathrm{C}$ and adding $\beta$-carotene to the melted lipid mixture, according to the formulations shown in Table 1. The carotenoid was added to the lipids after melting to minimize the degradation by the high temperature. The $\alpha$-tocopherol, when used, was added to the lipid phase. The different formulations and production conditions are described in Table 1. The hot surfactant solution (4\% of polysorbate 80 ) at $80^{\circ} \mathrm{C}$ was mixed with the melted lipid and subjected to ultra-agitation (Ultra Turrax IKA T25, IKA, Germany) at 9,000 rpm for $3 \mathrm{~min}$. Afterwards, the emulsion systems were magnetically stirred and cooled in an ice bath to $20^{\circ} \mathrm{C}$. The formulations were stored under refrigeration $\left(7-10^{\circ} \mathrm{C}\right.$, protected from exposure to light). 
Table 1 - Formulations used to prepare the solid lipid microparticles (PS80 = polysorbate 80).

\begin{tabular}{|c|c|c|c|c|c|c|}
\hline Particle & $\begin{array}{c}\text { Stearic acid } \\
(\%)\end{array}$ & $\begin{array}{c}\text { Sunflower oil } \\
(\%)\end{array}$ & $\begin{array}{c}\text { Polysorbate } 80 \\
(\%)\end{array}$ & $\begin{array}{c}\beta \text {-carotene } \\
(\%)^{*}\end{array}$ & $\begin{array}{c}\alpha \text {-tocopherol } \\
(\%)\end{array}$ & $\begin{array}{c}\text { Deionized } \\
\text { water }\end{array}$ \\
\hline 1 & 2.8 & 1.2 & 4 & 0.030 & 0.015 & q.s. $100 \mathrm{~mL}$ \\
\hline 2 & 2.8 & 1.2 & 4 & 0.030 & --- & q.s $100 \mathrm{~mL}$ \\
\hline
\end{tabular}

\section{Particle size distribution}

The particle size distribution was determined by laser diffraction using a Sald-201V instrument (Shimadzu Corporation, Japan) at $25^{\circ} \mathrm{C}$. The samples were diluted with ultra-pure water before the measurements.

\section{Differential scanning calorimetry (DSC)}

Thermal analysis by DSC was conducted using a ramp of $10^{\circ} \mathrm{C} / \mathrm{min}$ in the range of 0 to $100^{\circ} \mathrm{C}$ using a TA5000 calorimeter (TA Instruments, EUA). The reference was an empty aluminum pan. The CI (crystallinity index) was calculated from the melting enthalpies using Equation (1):

$$
\mathrm{CI}(\%)=\frac{\text { enthalpy LM }}{\text { enthalpy PL }} * \mathrm{fM} * 100
$$

where enthalpy LM is the melting enthalpy of the lipid mixture, enthalpy PL is the melting enthalpy of the pure lipid and $\mathrm{fM}$ is a factor that takes into account the concentration of solid lipid in the matrix $(0.90$ or 0.70 , for the mixtures containing 90 and $70 \%$ of solid lipid, respectively) (Severino et al. 2011).

\section{Wide-angle X-ray diffraction (WAXD)}

Wide-angle X-ray diffraction was performed in a Philips PW1710 diffractometer (Phillips, The Netherlands) with a copper anode at an X-ray wavelength of $\lambda=1.5418 \AA$. The measurements were obtained in a range of $2 \theta$ from zero to $40^{\circ}$ using steps of $0.02^{\circ}$ for both the lipid mixtures and the solid-lipid microparticles at room temperature. The interplanar spacings were calculated using Bragg's law (Equation (2)):

$$
\mathrm{d}=\frac{2 \lambda}{\sin \theta}
$$

where $d$ is the interplanar spacing, $\lambda$ is the incident $\mathrm{X}$-ray wavelength, and $\theta$ is the scattering angle (in radians).

\section{Determination of encapsulated $\beta$-carotene in the lipid microparticles}

The determination of encapsulated $\beta$-carotene was made by spectrophotometry. Briefly, the carotenoid was extracted with hexane after destabilization of the microparticulate system with sodium chloride (protocol adapted from Hentschel et al. 2008). Ultrasound was used to assist the destabilization of the dispersion and in the partitioning of the $\beta$-carotene to the hexane phase. After $\beta$-carotene extraction, the absorbance of the organic phase was measured at $450 \mathrm{~nm}$.

\section{Data presentation}

All the samples were prepared in three replicates and the data reported as the average value with standard deviation.

\section{RESULTS AND DISCUSSION}

\section{Choice of a suitable bulk lipid mixture}

The X-ray diffractograms of pure SA and mixtures of SA and SO are shown in Figure 1. In the "longspacing" region of the pure stearic acid diffractogram (low values of $2 \theta$ ), there were three diffraction peaks (at $0.133,0.80$ and $0.57 \mathrm{~nm}$ ) typical of this fatty acid (Moreno et al. 2007; Teixeira et al. 2010), which corresponded to reflections resulting from the interplanar spacing. It is important to remember that the polymorphism of carboxylic acids is different from the polymorphism of triacylglycerols. Normal saturated fatty acids exhibit complex polymorphic behaviour and the crystal forms are named $\mathrm{A}_{1}, \mathrm{~A}_{2}$, $\mathrm{A}_{3}, \mathrm{~A}_{\text {super }}, \mathrm{B}_{\mathrm{o}}, \mathrm{B}_{\mathrm{m}}, \mathrm{C}, \mathrm{E}_{\mathrm{o}}$ and $\mathrm{E}_{\mathrm{m}}$ (Timms 1984; Moreno et al. 2007). The results obtained by the WAXD indicated that the predominant form in the SA used in this study was the E form, but it was impossible to distinguish between the $\mathrm{E}_{\mathrm{o}}$ and $\mathrm{E}_{\mathrm{m}}$ subtypes.

The addition of SO caused shifts in these angles and increased their intensities in both the mixtures analyzed. The increase in the intensities in this region suggested that the structure was altered due 
to stretching of the acyl chains, thereby increasing the distance between the planes. In the "shortspacing" peaks region, pure stearic acid showed two very intense reflections at 0.42 and $0.38 \mathrm{~nm}$ that were associated with an orthorhombic structure (Timms 1984). This structure was also observed by the addition of sunflower oil, which provoked a sharp decrease in the intensity of the reflection at $0.42 \mathrm{~nm}$, and also diminished the intensity at $0.38 \mathrm{~nm}$. These alterations in the pure stearic-acid diffractogram indicate that its original structure was significantly modified by the presence of sunflower oil in the lipid matrix (Lin et al. 2007; Severino et al. 2011).

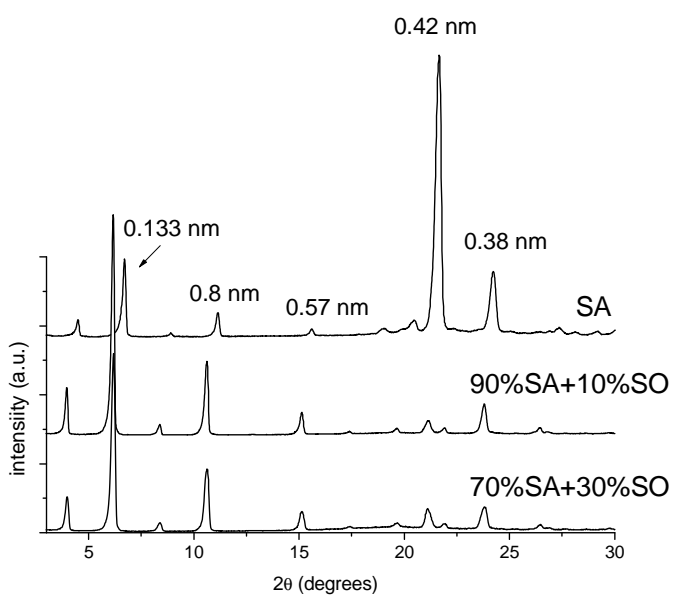

Figure 1 - WAXD analyses of bulk lipid mixtures composed of stearic acid (SA) and sunflower oil (SO).

Such important changes in the structure were confirmed by the calorimetric data obtained by DSC, shown in Table 2. The addition of sunflower oil, a liquid lipid consisting of a mixture of several triacylglycerols (mainly oleic and linoleic acids), favored the formation of less-ordered matrices containing imperfections in their structures. In other words, adding sunflower oil to the lipid matrix decreased the crystallinity, and either a less-ordered crystal, or an amorphous lipid matrix would be favorable for encapsulating more bioactive molecules (Attama et al. 2006; Lin et al. 2007; Attama et al. 2008). This change occurred especially in the samples containing $30 \% \mathrm{SO}$, in which the difference between the melting temperature $\left(\mathrm{T}_{\mathrm{m}}\right)$ and the onset temperature $\left(\mathrm{T}_{\mathrm{o}}\right)$ (here denoted as $\Delta \mathrm{T}$ ) was $8.2^{\circ} \mathrm{C}$. This difference was a very important parameter because it indicated the extent of the disorder of the lipid crystal structure. The calorimetric data suggested that the addition of $30 \%$ SO significantly altered the structure of the lipid matrix in comparison to the mixtures composed of $10 \%$ liquid lipid, in which the value of $\Delta \mathrm{T}\left(6.7^{\circ} \mathrm{C}\right)$ was practically the same as that calculated for the pure SA $\left(4.1^{\circ} \mathrm{C}\right)$.

A crystallinity index (CI) of $68.1 \%$ in the mixtures containing $30 \%$ sunflower oil confirmed the existence of a much lower degree of order of the crystal structure, which was of high importance for the encapsulation of solid-lipid particles because disorder allowed the creation of voids that accommodated larger amounts of bioactive molecules, minimized their expulsion, and could also modulate their release (Müller et al. 2002; Severino et al. 2011). The decrease in the melting enthalpies $\left(\Delta \mathrm{H}_{\mathrm{m}}\right)$ also reflected the large decrease in the degree of order of the lipid matrices due to the addition of SO. This decrease was quite large-from a $\Delta \mathrm{H}_{\mathrm{m}}$ equal to $219.2 \mathrm{~J} / \mathrm{g}$ for the pure stearic acid to $153.9 \mathrm{~J} / \mathrm{g}$ for the mixtures with $30 \%$ of sunflower oil, i.e., a decrease of $70.2 \%$.

Thus, because the addition of $30 \%$ SO was enough to cause a significant decrease in the crystallinity of the lipid matrix, this mixture was chosen to produce the $\beta$-carotene-loaded solid-lipid microparticles.

Table 2 - Calorimetric data obtained by DSC for the bulk lipid mixtures of stearic acid and sunflower oil.

\begin{tabular}{cccccc}
\hline Bulk lipid mixture & $\mathbf{T}_{\mathbf{0}}\left({ }^{\mathbf{0}} \mathbf{C}\right)$ & $\mathbf{T}_{\mathbf{m}}\left({ }^{\mathbf{0}} \mathbf{C}\right)$ & $\mathbf{\Delta} \mathbf{T}\left(\mathbf{~}^{\mathbf{0}} \mathbf{C}\right)$ & $\mathbf{\Delta} \mathbf{H}_{\mathbf{m}}(\mathbf{J} / \mathbf{g})$ & $\mathbf{C I}(\boldsymbol{\%})$ \\
\hline Stearic acid & 68.72 & 72.85 & 4.1 & 219.2 & -- \\
$90 \%$ SA+10\% SO & 65.41 & 72.11 & 6.7 & 182.4 & 89.1 \\
$70 \%$ SA+30\% SO & 62.62 & 70.8 & 8.2 & 153.9 & 68.1 \\
\hline
\end{tabular}


Characterization and shelf life of $\beta$-caroteneloaded solid lipid microparticles

Figure 2 shows the size distribution of the stearic acid microparticles samples during the storage period of seven months under refrigeration (7$10^{\circ} \mathrm{C}$ ) and in the dark. Evidently both the samples were very stable in terms of size distribution. In the case of particle 1 (with $\alpha$-tocopherol, Fig. 2 A), more than $90 \%$ of the particles were on average less than $2 \mu \mathrm{m}$ (with $40 \%$ less than $1 \mu \mathrm{m}$ ) after seven months (210 days) of storage. Dispersions of particle 2 (without $\alpha$-tocopherol, Fig. 2 B) were also stable in terms of size distribution, but the standard deviations of the measurements were always much higher than the standard deviations of dispersions of particle 1 . From these data, it was reasonable to consider the solid-lipid microparticulate systems as highly stable in terms of size during the storage period, especially the dispersions of particle 1 . The size stability could be explained by correlating several factors that have already been described in the literature (Duhkin et al. 2006; Grant et al. 2000). The interactions between the particle solid core and the hydrophilic and hydrophobic portions of the surfactant must be considered. Data from the literature (Tanaka et al. 2003) showed that the ability of the core acyl chains to interpenetrate the surface monolayer were dependent on their similarity in length - the more similar the hydrophobic portion and the core acyl chains were, the higher the interpenetration. In the case of the systems studied here, the surface chemistry and the dynamics of adsorption were most likely mainly influenced by the fact that all the components (stearic acid, sunflower oil and polysorbate 80 ) were all predominantly composed of C18 acyl chains, which certainly led to strong, favorable interchain interactions at the lipid coresurfactant interface, thereby conferring the stability.

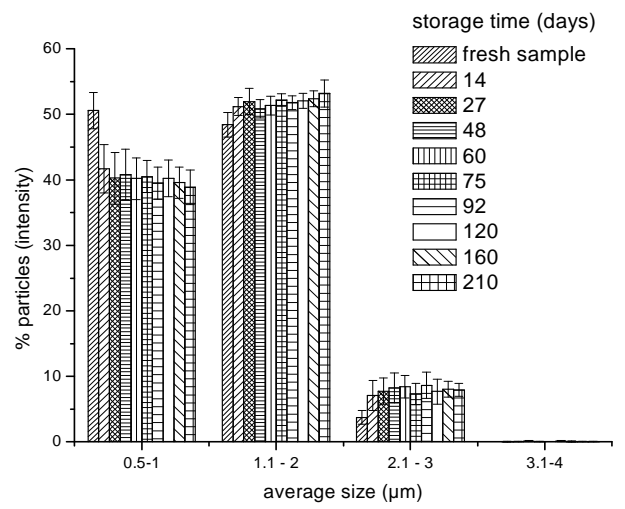

A

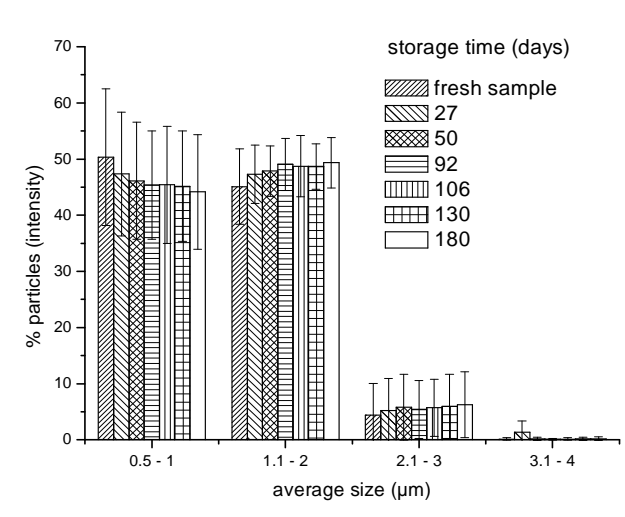

B

Figure 2 - Average particle size for $\beta$-carotene-loaded solid lipid microparticles over the storage period: (a) Particle 1 (with $\alpha$-tocopherol), (b) Particle 2 (without $\alpha$-tocopherol).

In addition, polysorbate molecules adsorbed onto hydrophobic surfaces form a robust separating layer (Graca et al. 2007). Such a configuration was responsible for a high capacity to dissipate energy, which could have conferred on the microparticles a higher capacity to resist tangential stresses, or compressive forces during collisions, thereby preventing the flocculation and coalescence during the storage. The capacity of the systems to preserve the encapsulated $\beta$-carotene over the storage period was supported by the temporal profiles in Figure 3. The presence of $\alpha$-tocopherol was essential for the preservation of encapsulated $\beta$-carotene in the stearic-acid microparticles. After 210 days, approximately $90 \%$ of the initial amount of the carotenoid was still preserved. However, after the same period, more than $90 \%$ of the initial amount had been degraded in dispersions of particle 2 (without $\alpha$-tocopherol). This behavior was certainly due to the antioxidant effect of $\alpha$ tocopherol, which acted by blocking a chain reaction and trapped oxygen, or oxygen radicals (McClements and Decker 2000; Hentschel et al. 2008).

The DSC results for the solid lipid microparticles are shown in Table 3. 


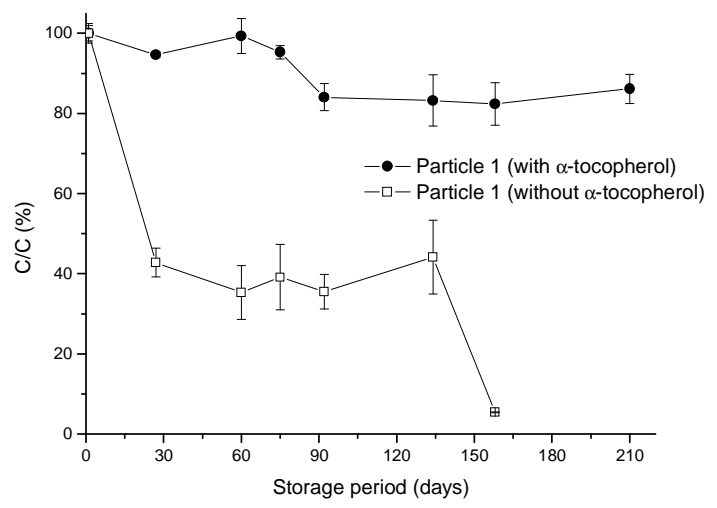

Figure 3 - $\beta$-carotene encapsulated in solid lipid microparticles over the storage period $(\mathrm{C}=$ concentration of $\beta$-carotene at the time of sampling, around $22 \mathrm{mg} / \mathrm{L}$ in both particles $; \mathrm{C}_{0}=$ concentration of $\beta$-carotene in fresh samples).

Table 3 - Calorimetric data obtained by DSC for the $\beta$-carotene-loaded solid lipid microparticles over the storage period.

\begin{tabular}{cccc}
\hline Particle & $\mathrm{T}_{\mathrm{o}}\left({ }^{\circ} \mathrm{C}\right)$ & $\mathrm{T}_{\mathrm{m}}\left({ }^{\circ} \mathrm{C}\right)$ & $\Delta \mathrm{H}_{\mathrm{m}}(\mathrm{J} / \mathrm{g})$ \\
\hline $1-$ fresh sample & 60.3 & 64.1 & 3.78 \\
$1-$ sample after 180 days & 59.7 & 65.0 & 5.14 \\
$2-$ fresh sample & 60.5 & 64.2 & 3.98 \\
$2-$ sample after 180 days & 65.1 & 67.4 & 6.53 \\
\hline
\end{tabular}

The dispersions of particle 1 did not show much alteration in thermal behavior at the end of the storage period; the melting enthalpy only increased by approximately $13 \%$, and there were no changes in the values of $T_{0}$ (onset temperature) and $\mathrm{T}_{\mathrm{m}}$ (melting temperature). However, the dispersions of particle 2 showed a large increase in $\mathrm{T}_{\mathrm{o}}, \mathrm{T}_{\mathrm{m}}$ and $\Delta \mathrm{H}_{\mathrm{m}}$, suggesting that the microstructure might had rearranged in such a way that more defects in the crystal structure developed. One reason for the occurrence of such a destabilization detected by DSC in the dispersions of particle 2 could have been lipid oxidation, although this was not monitored over the storage period. During the production of the particles, the mixture of stearic acid and sunflower oil was exposed to a high temperature $\left(80^{\circ} \mathrm{C}\right)$. Although the exposure was not prolonged (i.e., enough time for the stearic acid to melt completely, less than 10 minutes), the heat could have initiated the phenomenon of heatinduced oxidation, leading to the formation of prooxidant agents. These pro-oxidant agents could have continued to react and feed auto-oxidation reactions, both in the unsaturated chains of the triacylglycerols in sunflower oil and $\beta$-carotene. The lipid oxidation might have been enough to alter the composition of the lipid matrix, thereby altering the crystal structure of the particles as detected by DSC. The WAXD data, obtained only for dispersions of particle 1 indicated that there were no significant temporal modifications in the crystal structure during the storage (Fig. 4).

The X-ray diffractometry data showed only a slight modification in the crystalline characteristics in particle 1. After the first month of storage, a small peak, approximately $20=6.1^{\circ}$, appeared, indicating the changes in the hydrocarbon chains of the lipids, which might have stretched during the storage. The spectra obtained during the first and sixth months of storage, however, were very similar in terms of the location and intensity of the peaks. This indicated that a transition to highly ordered lipid particles did not occur during the storage. 


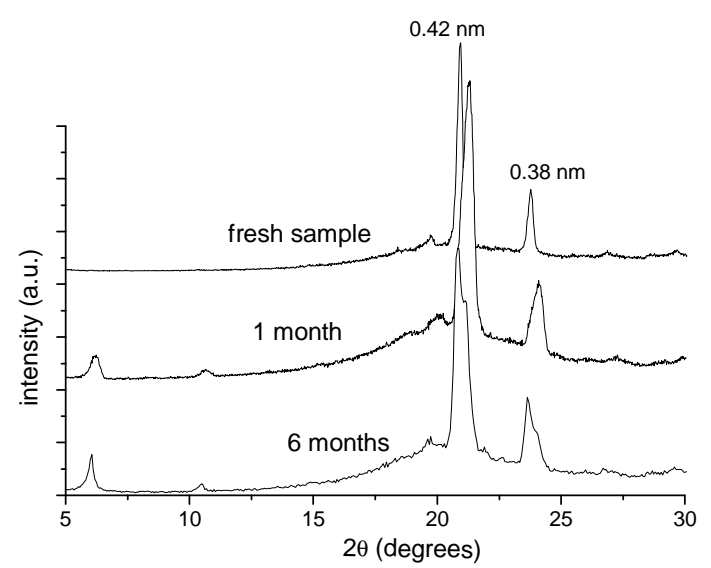

Figure 4 - WAXD data of $\beta$-carotene-loaded solid lipid microparticles over the storage period.

The high stability of the $\beta$-carotene-loaded lipid microparticles that was observed in these studies, both in terms of the size and preservation of the encapsulated carotenoid, agreed with other results found in the literature for similar systems. Hentschel et al. (2008) produced $\beta$-caroteneloaded solid lipid particles of propylene glycol monostearate (ALDO PGHMS®) stabilized with polysorbate 80 . The carotenoid was dispersed in sunflower oil (Lucarotin SUN 10®, from BASF) and the addition of $\alpha$-tocopherol was tested to protect $\beta$-carotene against oxidation. There was aggregation of the particles stored at low temperature $\left(4-8^{\circ} \mathrm{C}\right)$ for 30 weeks and the presence of $\alpha$-tocopherol was necessary to preserve the encapsulated $\beta$-carotene, which was similar to the present findings. Trombino et al. (2009), who studied encapsulated $\beta$-carotene, made a comparison between the two types of solid lipid particles, one composed of ferulic acid and the other of stearic acid, both stabilized with a mixture of sodium taurocholate and polysorbate 20 , in terms of preservation of the carotenoid. Both types of particles were exposed to sunlight for three months at room temperature $\left(28-30^{\circ} \mathrm{C}\right)$. Both particle systems were capable of preserving the encapsulated bioactive compound over the storage time, although the ferulic-acid particles were slightly more efficient than those containing stearic acid. In another study, Tripplet II and Rathman (2009) produced $\beta$-carotene-loaded solid lipid particles with pure stearic acid and stabilized with lecithin and sodium taurocholate. The system was able to preserve the concentration of the carotenoid for 30 days of storage at room temperature and did not undergo any changes in average particle size. These results indicated that a stearic chain was a good choice for producing the solid lipid particles to protect the $\beta$-carotene from degradation. However, none of the studies without the addition of antioxidants monitored the stability for more than 90 days of storage, as the present study did.

An explanation for the higher stability shown by the dispersions of particle 1 was given by Cornacchia and Roos (2011b) who produced solid lipid particles encapsulating $\beta$-carotene composed of hydrogenated palm kernel oil (HPKO) and stabilized with whey protein isolate (WPI). The particles showed a residual concentration of carotenoid of $80-90 \%$ after 28 days of storage at $15^{\circ} \mathrm{C}$. Only the system stabilized with a higher concentration of WPI (3\%) was capable of protecting the $\beta$-carotene over the storage period. The authors concluded that the low capacity of protection demonstrated by the solid particles was due to the exclusion of $\beta$-carotene from the HPKO crystalline network and its confinement in the regions of reduced volume. The problem was that these regions were most likely the dispersing phase for $\beta$-carotene, oxidative agents and any dissolved oxygen. Another reason for the low capacity of preservation of the $\beta$-carotene in the solid lipid particles of HPKO could have been the location of the carotenoid in the structure, as it might have been forced to migrate to the surface of the particles due to the formation of lipid crystals (Okuda et al. 2005; Helgason et al. 2009; 
Cornacchia and Roos 2011b). The location at the surface would facilitate the contact with prooxidant species present in the aqueous phase. Thus, a partially solid matrix that allows the formation of small domains, in which $\beta$-carotene would be placed, would be more effective for protecting the compound (Cornacchia and Roos 2011a). This observation precisely reflected the result observed in the present study, in which solid lipid particles were produced with a mixture of $70 \%$ stearic acid and $30 \%$ sunflower oil.

Helgason et al. (2009) showed polysorbate 80 was not an effective surfactant to protect the $\beta$-carotene encapsulated in tripalmitin lipid particles. However, the system was only composed of solid triacylglycerols, and the particles most likely crystallized from the interior to the surface. The carotenoid was expelled from the highly organized crystal subcells and was forced to be on the droplet surface in closer proximity to pro-oxidants in the aqueous phase. Such an expulsion of the $\beta$ carotene to the surface most likely did not occur in this study because the particles were produced with a mixture of lipids, which resulted in a highly disorganized particle structure, as indicated by DSC and WAXD results.

\section{CONCLUSIONS}

From the data shown here, it could be concluded that it was possible to produce the solid lipid microparticles composed of stearic acid and sunflower oil and capable of encapsulating $\beta$ carotene and protecting the carotenoid from degradation over a long storage period (seven months). The systems with high protective action did not undergo significant changes in microstructure, according to the data obtained by the WAXD and DSC. The presence of $\alpha$ tocopherol was essential for the preservation of $\beta$ carotene due to the action of the former as a chainreaction blocker, or oxygen/oxygen radical trap. The high stability observed, except in the stearicacid microparticles without $\alpha$-tocopherol, appeared to be caused by a set of factors acting in conjunction, including the chemical compatibility of all of the components of the formulations tested, as well as the ability of polysorbates to provide the robustness to the stabilizing monolayers around the solid lipid particles, thus avoiding the aggregation, or coalescence and preventing the destabilization by coalescence, or aggregation. The choice of a suitable lipid mixture, which affected the crystallization of the particles, was decisive for the preservation of encapsulated $\beta$-carotene.

\section{ACKNOWLEDGEMENTS}

The authors thank Fundação de Amparo à Pesquisa do Estado de São Paulo (FAPESP) and Conselho Nacional de Pesquisa e Desenvolvimento (CNPq) for the scholarships (G.V.L.G., grant number 2009/02028-4; T.R.B., grant number $119927 / 2009-8), \mathrm{CNPq}$ for the financial support (grant number 475786/2008-4), and Ednelí Monterrey-Quintero for the laser diffraction analyses.

\section{REFERENCE}

Attama AA, Müller-Goymann CC. Effect of beeswax modification on the lipid matrix and solid lipid nanoparticle crystallinity. Coll Surf A: Phys Eng Asp. 2008; 315: 189-195.

Attama AA, Schicke BC, Müller-Goymann CC. Further characterization of theobroma oil-beeswax admixtures as lipid matrices for improved drug delivery systems. Eur J Pharm Biopharm. 2006; 64(3): 294-306.

Boon CS, McClements DJ, Weiss J, Decker EA. Factors influencing the chemical stability of carotenoids in foods. Crit Rev Food Sci Nut. 2010; 50(6): 515-532.

Cao-Hoang L, Fougere R, Wache Y. Increase in stability and change in supramolecular structure of $\beta$ carotene through encapsulation into polylactic acid nanoparticles. Food Chem. 2011; 124(1): 42-49.

Cornacchia L, Roos YH. Stability of $\beta$-carotene in protein-stabilized oil-in-water delivery systems. $J$ Agric Food Chem. 2011a; 59(13): 7013-702.

Cornacchia L, Roos YH. State of dispersed lipid carrier and interface composition as determinants of betacarotene stability in oil-in-water emulsions. J Food Sci. 2011 b; 76 (8): C1211-C1218.

Damodaran S Parkin, KL, Fennema, OR. Fennema's Food Chemistry. $4^{\text {th }}$ ed. Boca Raton: CRC Press; 2010.

Duhkin SS, Sjöblom J, Saether O. An experimental and theoretical approach to the dynamic behaviour of emulsions. In: J. Sjöblom, editor. Emulsions and emulsion stability. Boca Raton: Taylor and Francis, $1-105 ; 2006$. 
Fraser PD, Bramley PM. The biosynthesis and nutritional uses of carotenoids. Prog Lipid Res. 2004; 43(6): 228-265.

Gonnet M, Lethuaut L, Boury F. New trends in encapsulation of liposoluble vitamins. J Control Rel. 2010; 146(3): 276-290.

Graca M, Bongaerts JHH, Stokes JR, Granick S. Friction and adsorption of aqueous polyoxyethylene (Tween) surfactants at hydrophobic surfaces. $J$ Colloid Interface Sci. 2007; 315(2): 662-670.

Grant LM, Ederth T, Tiberg FF. Influence of surface hydrophobicity on the layer properties of adsorbed nonionic surfactants. Langmuir 2000; 16(5): 22852291.

Helgason T, Awad TS, Kristbergsson K, Decker EA, McClements, DJ, Weiss, J. Influence of polymorphic transformations on gelation of tripalmitin solid lipid nanoparticle suspensions. J Am Oil Chem Soc. 2008; 85: 501-511.

Helgason T, Awad TS, Kristbergsson K, Decker EA, McClements DJ, Weiss J. Impact of surfactant properties on oxidative stability of $\beta$ - carotene encapsulated within solid lipid nanoparticles. J Agric Food Chem. 2009; 57 (3): 8033-8040.

Hentschel A, Gramdorf S, Muller RH, Kurz T. $\beta$ Carotene-loaded nanostructured lipid carriers. J Food Sci. 2008; 73 (1): 1-6.

Lin X, Li X, Zheng LQ,Yu L, Zhang Q, Liu W. Preparation and characterization of monocaprate nanostructured lipid carriers. Colloids Surf A: Physicochem Eng Asp. 2007; 311(1): 106-111.

McClements DJ. Design of Nano-Laminated Coatings to Control Bioavailability of Lipophilic Food Components. J Food Sci. 2010; 75 (1): 30-42.

McClements DJ, Decker EA. Lipid oxidation in oil-inwater emulsions: impact of molecular environment on chemical reactions in heterogeneous food systems. $J$ Food Sci. 2000; 65(8): 1270-1282.

McClements DJ, Li Y, 2010. Structured emulsion-based delivery systems: Controlling the digestion and release of lipophilic food components. Adv Coll Interf Sci. 2010; 159 (2): 213-228.

Moreno E, Cordobilla R, Calvet T, Cuevas-Diarte MA, Gbabode G, Negrier P, Mondieig D, Ooonk HAJ. Polymorphism of even saturated carboxylic acids fron n-decanoic to n-eicosanoic acid. New J Chem. 2007; 31 (6): 947-957.

Müller RH, Radtke M, Wissing SA. Solid lipid nanoparticles (SLN) and nanostructured lipid carriers (NLC) in cosmetic and dermatological preparations. Adv Drug Deliv Rev. 2002; 54 (Supplement): S131S155.

Nik AM, Corredig M, Wright AJ. Release of lipophilic molecules during in vitro digestion of soy proteinstabilized emulsions. Mol Nutr Food Res. 2011; 55 (Supplement 2): S278-S289.
Okuda S, McClements DJ, Decker EA, Impact of lipid physical state on the oxidation of methyl linoleate in oil-in-water emulsions. J Agric Food Chem. 2005; 53(24): 9264-9628.

Papaioannou EH, Liakopoulou-Kyriakides M. Substrate contribution on carotenoids production in Blakeslea trispora cultivations. Food Biop Process. 2010; 88 (2): 305-311.

Ratnam DV, Ankola DD, Bhardwaj V, Sahana DK, Kumar MNVR. Role of antioxidants in prophylaxis and therapy: A pharmaceutical perspective. J Control Rel. 2006; 113 (2): 189-207.

Severino P, Pinho SC, Souto EB, Santana MHA. Polymorphism, crystallinity and hydrophilichydrophobic balance of stearic acid and stearic acidcapric/caprylic triglyceride matrices for production of stable nanoparticles. Coll Surf B:Bioint. 2011; 86 (1): 125-130.

Shukat R, Relkin P. Lipid nanoparticles as vitamin matrix carriers in liquid food systems: on the role of high-pressure homogenisation, droplet size and adsorbed materials. Coll Surf B:Bioint. 2011; 86 (1): 119-124.

Tanaka M, Saito H, Arimoto I, Nakano M, Handa T. Evidence for interpenetration of core triglycerides into surface phospholipid monolayers in lipid emulsions. Langmuir. 2003; 19 (13): 5192-5196.

Teixeira ACT, Garcia AR, Ilharco LM, Gonçalves da Silva AMPS, Fernandes AC. Phase behaviour of oleanolic acid, pure and mixed with stearic acid: interactions and crystallinity. Chem Phys Lip. 2010; 163 (7): 655-666.

Timms RE. Phase behaviour of fats and their mixtures. Prog Lip Res. 1984; 23(1): 1-38.

Tripplet II MD, Rathman JF. Optimization of betacarotene loaded solid lipid nanoparticles preparation using a high shear homogenization technique. $J$ Nanop Res. 2009; 11 (3): 601-614.

Trombino S, Cassano R, Muzzalupo R, Pingitore A, Picci N. Stearyl ferulate-based solid lipid nanoparticles for the encapsulation and stabilization of $\beta$-carotene and $\alpha$-tocopherol. Colloids Surf B: Bioint. 2009; 72 (2): 181-187.

Wang P, Liu HJ, Mei XY, Nakajima M, Yin LJ. Preliminary study into the factors modulating $\beta$ carotene micelle formation in dispersions using an in vitro digestion model. Food Hydrocoll. 2012; 26 (2): 427-433.

Yuan Y, Gao Y, Zhao J, Mao L. Characterization and stability evaluation of $\beta$-carotene nanoemulsions prepared by high pressure homogenization under various emulsifying conditions. Food Res Int. 2008; 41(1): 61-68.

Received: April 27, 2012; Accepted: June 03, 2013. 
